\title{
Biomarkers of treatment efficacy in patients with chronic spontaneous urticaria
}

\author{
${ }^{1}$ Allergy and Clinical Immunology Department, Centro Medico Docente La Trinidad, Caracas, Venezuela \\ ${ }^{2}$ Allergy Service, Clínica El Avila, Caracas, Venezuela \\ ${ }^{3}$ Allergy Service, Centro Médico de Caracas, Caracas, Venezuela \\ ${ }^{4}$ Dermatology Service, Centro Médico de Caracas, Caracas, Venezuela
}

\section{KEY WORDS}

antihistamines; biomarkers; chronic urticaria; cyclosporine; omalizumab

\author{
Corresponding author \\ Mario Sánchez-Borges \\ Clínica El Avila, 6a transversal Urb. Altamira \\ piso 8, consultorio 803 \\ Caracas 1060, Venezuela \\ Phone: +582122615284 \\ Fax: +582122615284 \\ E-mail: sanchezbmario@gmail.com
}

Doi

10.23822/EurAnnACI.1764-1489.24

\begin{abstract}
Summary
Background. Currently there are no biomarkers useful to predict the future evolution and the therapeutic response in patients with chronic spontaneous urticaria (CSU). Objective. To review the available information on biomarkers that might be applied for the follow up of the response to guideline recommended therapies for CSU. Methods. A review of the medical literature on CSU potential clinical and laboratory biomarkers in PubMed and MEDLINE including the terms urticaria, chronic urticaria, chronic idiopathic urticaria, chronic spontaneous urticaria, antihistamines $(A H s)$, omalizumab $(O M A)$, cyclosporine $(C y A)$, and treatment. Results. Clinical manifestations that were associated to poor responses to AHs were atopy, asthma, rhinitis I rhinosinusitis, thyroid disease, hypertension, higher disease activity and duration. Laboratory markers of AH resistance that have been reported include Complement C5 a fraction, Autologous Serum Skin Test (ASST), Basophil Activation Test (BAT), D-dimer and LCN2 adipokine. Basophil Histamine Release Assay (BHRA), ASST, and basophil CD203c-upregulating activity in the serum correlated with favorable response to OMA, whereas disease duration and severity, BAT, BHRA, and D-dimer levels were associated with better responses to CyA. Conclusion. Some promising biomarkers useful for patient management in CSU, have been identified in the literature. There is, however, an urgent need of new, easy-to-perform markers that can be made widely available for the optimal care of patients suffering CSU.
\end{abstract}

\section{Introduction}

Chronic spontaneous urticaria (CSU) is a highly prevalent condition affecting 0.3 to $0.6 \%$ of the population $(1,2)$. Although currently CSU is regarded as a systemic inflammatory disease, its pathogenesis is not completely understood (3). In consequence, treatment recommendations are in general oriented to the control and prevention of symptoms and exacerbations (4). Current international guidelines recommend a 3-step system, beginning with second generation, non-sedating antihistamines at conventional doses, followed by increased doses up to 4 times if there is no response after 2 weeks. For patients who do not respond to antihistamines, a third line therapy consists of adding omalizumab, cyclosporine or montelukast (4).
When a new patient suffering CSU is diagnosed, it would be important for the treating physician to have available clinical biomarkers, useful to predict the future evolution of the disease and the most likely response to the treatment. A previous article from our institutions presented a summary of the clinical and laboratory markers that have been proposed for the assessment of the severity of CSU (5). The present article reviews the information currently available on biomarkers that could be utilized to identify who are the patients more suitable for a particular form of treatment. We have to mention that in this literature search, we did not find adequate investigations dealing with clinical or complementary markers associated to a favorable or negative response to corticosteroids. 


\section{Methods}

A review of the medical literature was performed on PubMed and MEDLINE, including the terms urticaria, chronic urticaria, chronic idiopathic urticaria, chronic spontaneous urticaria, antihistamines, omalizumab, cyclosporine, and treatment. All reference types were included in the search.

\section{Results}

\section{Therapeutic guidelines for chronic spontaneous urticaria}

Current international guidelines for the management of urticaria and angioedema recommend therapy with conventional or increased doses of second generation antihistamines (AHs) for patients with chronic urticaria (CU) (4).

Although the definition of antihistamine-resistant urticaria, as given in the guidelines, is "urticaria which is not controlled after updosing of non-sedating AHs up to 4 times the usual dose" (4), other investigators have used their own definitions. For example, the following have been proposed: "steroid dependent rash poorly responsive to multiple $\mathrm{AHs}$ and immunosuppressive agents" (6), "patients not responding to $10 \mathrm{mg}$ cetirizine per day for 1 week" (7), or "those on $5 \mathrm{mg}$ of levocetirizine or $10 \mathrm{mg}$ of cetirizine twice a day for 15 days and a combination of fexofenadine $180 \mathrm{mg}$ and hydroxyzine $25 \mathrm{mg}$ for another 15 days without $>50 \%$ reduction of baseline urticaria activity scores" (8). Between 40 and $65 \%$ of patients with CSU do not respond to the treatment with AHs even at doses 4 times higher than the approved ones (9). Patients refractory to increased doses of $\mathrm{H} 1$ receptor antagonists require the addition or substitution of alternative agents, being corticosteroids, cyclosporine and omalizumab more efficacious than others, such as H2-receptor antagonists, leukotriene antagonists, hydroxychloroquine, dapsone, colchicine, and sulfasalazine. Long term use of corticosteroids is discouraged due to safety concerns, while they are recommended exclusively for short periods of time during disease exacerbations.

\section{Biomarkers of response to antihistamines}

Nonsedating AHs are the first line of therapy for the control of symptoms in patients with CSU (4). As mentioned, for patients who do not respond to approved doses, the recommendation is to administer increased doses of second generation AHs. This is based on controlled studies showing better efficacy (and acceptable tolerance) of higher doses over the usual doses, and also its superiority when compared to the combination of two different AHs $(4,10,11)$. However, updosing antihistamine to obtain a better control of CSU is not always successful (12).
Insufficient response to treatment is a defining feature of severe CSU. In general, there is scarce information on the factors that may predict a favorable therapeutic response. In a recent study, it was reported that antihistamine-resistant $\mathrm{CU}$ was associated to other clinical indicators of severity, including atopic asthma, rhinitis and rhinosinusitis, thyroid disease and hypertension (13).

Another investigation showed that antihistamine-resistant $\mathrm{CU}$ shows increased complement $\mathrm{C} 5 \mathrm{a}$ fraction in the serum, higher disease activity, longer duration of wheals and higher positivity of the autologous serum skin test (ASST) (14). According to Staubach and coworkers, and to Ye and coworkers ASST and Basophil Activation Test (BAT) positivity is associated with a poor response to antihistamine treatment in patients with CU $(15,16)$. However, the usefulness of ASST to predict the response to treatment with $\mathrm{AHs}$ and corticosteroids has been challenged by Belot and coworkers, who proposed that ASST results do not have bearing on the treatment and are not associated with greater resistance to antihistamine treatment (17). In a different approach, Asero has proposed that elevated D-dimer plasma levels should be considered a marker of antihistamine-resistant CU (18). Plasma D-dimer levels were elevated in 0 of 41 patients $(0 \%)$ showing an "excellent" response to cetirizine, 3 of 14 (21\%) patients showing a "good" response, 3 of $5(60 \%)$ patients showing a "partial" response, 18 of 23 (78\%) patients showing a "poor" response, and 7 of $8(88 \%)$ non-responders. On comparing patients with a disease of similar severity showing either normal or elevated D-dimer levels, it turned out that the latter were much more frequently cetirizine-resistant.

We found no published evidence that failure to respond to treatment in adult CSU patients is linked to long disease duration. In children with CSU, remission rates of patients who respond to standard dosed antihistamine treatment are reportedly higher than those of patients who require high-dose antihistamine or combination medications, indicating that urticaria controlled by a standard dose of antihistamine may predict a shorter time to remission in the pediatric CSU population. The mean duration of disease at the first visit in the non-remission group was higher than in the remission group, at the end of the study (19). An imbalance in pro- and anti-inflammatory adipokines in CU patients has been recently observed by Trinh and coworkers. Mean levels of serum Lipocalin-2 (LCN2), TNF- $\alpha$, IL-6, and IL-10 were significantly higher in CU patients than in controls, whereas adiponectin levels were significantly lower in patients with CU than in controls. While serum IL-6 levels were significantly higher in refractory $\mathrm{CU}$ patients, compared to responsive CU individuals, LCN2 showed a direct relationship with the Urticaria Activity Score (UAS). Authors suggested that LCN2 could be a differential marker for disease activity and the clinical responses to antihistamine treatment in CU patients (20). 
Table I - Biomarkers of antihistamine resistance in chronic spontaneous urticaria.

\begin{tabular}{lclc}
\hline Clinical & References & Laboratory & References \\
\hline asthma & 13 & complement C5a fraction & 14 \\
\hline rhinitis / rhinosinusitis & 13,21 & positivity of the autologous serum skin tests (ASST) & $14-16$ \\
\hline thyroid disease & 13 & basophil activation test & 15,16 \\
\hline hypertension & 13 & D-dimer & 18 \\
\hline higher disease activity & 14 & LCN2 adipokine & 19 \\
\hline longer duration of wheals & 14,15 & & \\
\hline atopy & 21 & & \\
\hline
\end{tabular}

According to one study from Taiwan, the presence of atopy and allergic rhinitis is associated with a poor therapeutic response to second generation antihistamines, since non-responders tended to have atopy, especially allergic rhinitis (21). Potential biomarkers of response to AHs are presented in Table $\mathbf{I}$.

\section{Biomarkers of response to omalizumab}

The efficacy and safety of recombinant monoclonal anti-human $\operatorname{IgE}$ (omalizumab) in the treatment of chronic urticaria was clearly established in various seminal studies (22-24). Recent investigations have tried to identify possible markers of response to omalizumab (Table II).

According to Gericke et al., there are significant correlations between a positive Basophil Histamine Release Assay (BHRA) and ASST and the time to symptom relief with omalizumab. The fact that a positive BHRA is predictive of a slow response to omalizumab, suggests that omalizumab works via reducing FceRI expression in these patients (25).

In a second study that investigated markers of the response to omalizumab, Palacios et al. reported that the lack of basophil CD203c-upregulating activity in the serum of patients with $\mathrm{CU}$ correlates with the clinical response to this monoclonal anti-IgE antibody (26).

Table II - Biomarkers of omalizumab effectiveness in chronic spontaneous urticaria.

\begin{tabular}{lc}
\hline Laboratory & References \\
\hline basophil histamine release assay (BHRA) & 25 \\
\hline ASST & 25 \\
\hline $\begin{array}{l}\text { lack of basophil CD203c-upregulating activity } \\
\text { in the serum }\end{array}$ & 26 \\
\hline D-dimer plasma levels & 29 \\
\hline
\end{tabular}

It has been reported that serum IL-31 levels of patients with CSU are significantly higher than in healthy controls (27). A recent investigation reported that omalizumab, but not placebo, signifcantly reduced IL-31 levels of patients with CSU. Nevertheless, no correlation between IL-31 and urticaria activity score, wheal, or itch scores were present (28). From those results authors concluded that the functional relationship of IL-31 to the pathogenesis and symptom severity of CSU remains to be clarified.

New data from Asero and coworkers has demonstrated that D-dimer plasma levels parallel the clinical response to omalizumab (29).

\section{Biomarkers of response to cyclosporine}

The second alternative drug that has been shown to be effective for patients with treatment-resistant CSU is cyclosporine A (30-32).

Although effective, due to its nephrotoxicity it is advised that this medication is managed under the supervision of specialists experienced in its use.

Patients with CSU with positive BAT results respond better to cyclosporine treatment than those with negative BAT results (30). This finding was further supported by Iqbal's paper, who reported that in patients treated with cyclosporine, a positive BHRA indicated a higher probability of response (33). Furthermore,

Table III - Biomarkers of cyclosporine effectiveness in chronic spontaneous urticaria.

\begin{tabular}{lclc}
\hline Clinical & References & Laboratory & References \\
\hline disease duration & 33 & BAT & 27 \\
\hline initial severity & 33 & BHRA & 31 \\
\hline & & D-dimer & 33,34
\end{tabular}


shorter duration of the disease and higher initial severity predict a successful response to treatment with cyclosporine (34).

Baseline D-dimer levels show a highly significant negative correlation with the response to cyclosporine. (35). Other authors have postulated that baseline D-dimer is a good marker of disease activity in most patients with CSU, and may be useful to monitor the clinical response to cyclosporine treatment (36) (Table III).

\section{Conclusions}

Due to the scarcity of published investigations, few markers are currently available for predicting the response to treatment in patients with CSU. However, some clinical features, such as disease activity and duration as well as laboratory markers that include BAT, BHRA, ASST, and D-dimer, are potentially useful for such purposes. Additional studies that provide easy to perform and widely available markers are needed in order to deliver a better care for CSU patients.

\section{Conflict of interest}

M. Sánchez-Borges has received honorary for lecturing from Novartis Pharma AG. F. Caballero-Fonseca has received speaker honorary from Sanofi Aventis. A. Capriles-Hulett and L. González-Aveledo declare that they do not have conflicts of interest.

\section{Funding}

This work was supported by investigator's funds.

\section{References}

1. Zuberbier T, Balke M, Worm M, Edenharter G, Maurer M. Epidemiology of urticaria: a representative cross-sectional population survey. Clin Exp Dermatol 2010; 35(8):869-73.

2. Gaig P, Olona M, Muñoz Lejarazu D, Caballero MT, Domínguez FJ, Echechipia S, García Abujeta JL, Gonzalo MA, Lleonart R, Martínez Cócera C, Rodríguez A, Ferrer M. Epidemiology of urticaria in Spain. J Investig Allergol Clin Immunol 2004; 14:214-20.

3. Sánchez-Borges M, Asero R, Ansotegui IJ, Baiardini I, Bernstein JA, Canonica GW, Gower R, Kahn DA, Kaplan AP, Katelaris C, Maurer M, Park HS, Potter P, Saini S, Tassinari P, Tedeschi A, Ye YM, Zuberbier T; WAO Scientific and Clinical Issues Council. Diagnosis and treatment of urticaria and angioedema: a worldwide perspective. World Allergy Organ J 2012; 5:125-47.

4. Zuberbier T, Aberer W, Asero R, Bindslev-Jensen C, Brzoza Z, Canonica GW, Church MK, Ensina LF, Giménez-Arnau A, Godse K, Gonçalo M, Grattan C, Hebert J, Hide M, Kaplan A, Kapp A, Abdul Latiff AH, Mathelier-Fusade P, Metz M, Nast A, Saini SS, Sánchez-Borges M, Schmid-Grendelmeier P, Simons FE, Staubach P, Sussman G, Toubi E, Vena GA, Wedi B, Zhu XJ, Maurer M; European Academy of Allergy and Clinical Immunology; Global Allergy and Asthma European Network; European Dermatology
Forum; World Allergy Organization. The EAACI / GA(2)LEN / EDF / WAO Guideline for the definition, classification, diagnosis, and management of urticaria: the 2013 revision and update. Allergy 2014; 69:868-87.

5. Sánchez-Borges M, Caballero-Fonseca F, Capriles-Hulett A, González-Aveledo L, Maurer M. Factors linked to disease severity and time to remission in patients with chronic spontaneous urticaria. J Eur Acad Dermatol Venereol 2017 (in press).

6. Pérez A, Woods A, Grattan CE. Methotrexate: A useful steroid-sparing agent in recalcitrant chronic urticaria. Br J Dermatol 2010; 162:191-4.

7. Okubo Y, Shigoka Y, Yamazaki M, Tsuboi R. Double dose of cetirizine hydrochloride is effective for patients with urticaria resistant: A prospective, randomized, non-blinded, comparative clinical study and assessment of quality of life. J Dermatol Treat 2013; 24:153-60.

8. Sharma VK, Singh S, Ramam M, Kumawat M, Kumar R. A randomized placebo-controlled double-blind pilot study of methotrexate in the treatment of $\mathrm{H} 1$ antihistamine-resistant chronic spontaneous urticaria. Indian J Dermatol Venereol Leprol 2014; 80:112-8.

9. Kaplan AP. Treatment of chronic spontaneous urticaria. Allergy Asthma Immunol Res 2012; 4:326-33.

10. Sánchez-Borges M, Caballero-Fonseca F, Capriles-Hulett A. Treatment of recalcitrant chronic urticaria with nonsedating antihistamines: is there evidence for updosing? J Investig Allergol Clin Immunol. 2013; 23:141-4.

11. Sánchez-Borges M, Ansotegui I, Jimenez JM, Rojo MI, Serrano C, Yañez A. Comparative efficacy of non-sedating antihistamine updosing in patients with chronic urticaria. World Allergy Organ J 2014; 7(1):33.

12. Asero R. Chronic unremitting urticaria: is the use of antihistamines above the licensed dose effective? A preliminary study of cetirizine at licensed and above-licensed doses. Clin Exp Dermatol 2007; 32:34-8.

13. Sánchez-Borges M, Tassinari S, Flores A. Epidemiologic features in patients with antihistamine-resistant chronic urticaria. Rev Alergia Mex 2015; 62:279-86.

14. Huilan Z, Bihua L, Runxiang L, Jiayan L, Luyang L, Zhenjie L. Features of antihistamine-resistant chronic urticaria and chronic urticaria during exacerbation. Indian J Dermatol 2015; 60:323.

15. Staubach P, Onnen K, Vonend A, Metz M, Siebenhaar F, Tschentscher I, Opper B, Magerl M, Lüdtke R, Kromminga A, Maurer M. Autologous whole blood injections to patients with chronic urticaria and a positive autologous serum skin test: A placebo-controlled trial. Dermatology 2006; 212:150-9.

16. Ye YM, Park JW, Kim SH, Ban GY, Kim JH, Shin YS, Lee HY, Park HS on behalf of the PRANA Group. Prognostic Factors for Chronic Spontaneous Urticaria: A 6-Month Prospective Observational Study. Allergy Asthma Immunol Res 2016; 8:115-23.

17. Bèlot V, Desbois I, Martin L, Valat C, Lorette G, Machet L. Assessment of the usefulness of autologous serum skin testing in chronic urticaria: A retrospective single-centre study of 74 patients. Ann Dermatol Venereol 2010; 137:444-50.

18. Asero R. D-dimer: A biomarker for antihistamine-resistant chronic urticaria. J Allergy Clin Immunol 2013; 132:983-6.

19. Eser I, Yologlu N, Baydemir C, Aydogan M. The predictive factors for remission of chronic spontaneous urticaria in childhood: Outcome from a prospective study. Allergol Immunopathol (Madr) 2016 Jul 28. Pii: S0301-0546(16)30073-8. 
20. Trinh HKT, Ban G-Y, · Lee H-Y, · Park H-S, Ye-M. Altered Systemic Adipokines in Patients with Chronic Urticaria. Int Arch Allergy Immunol 2016; 171:102-10.

21. Lee HC, Hong JB, Chu CY. Chronic idiopathic urticaria in Taiwan: A clinical study of demographics, aggravating factors, laboratory findings, serum autoreactivity and treatment response. J Formos Med Assoc 2011; 110:175-82.

22. Kaplan A, Ledford D, Ashby M, Canvin J, Zazzali JL, Conner E, et al. Omalizumab in patients with symptomatic chronic idiopathic/ spontaneous urticaria despite standard combination therapy. J Allergy Clin Immunol 2013; 132:101-9.

23. Maurer M, Rosén K M.D., Hsieh HJ, Saini S, Grattan C, Gimenéz-Arnau A, Agarwal S, Doyle R, Canvin J, Kaplan A, Casale T. Omalizumab for the Treatment of Chronic Idiopathic or Spontaneous Urticaria. N Engl J Med 2013; 368:924-93.

24. Saini SS, Bindslev-Jensen C, Maurer M, Grob JJ, Bülbül Basken E, Bradley MS, et al. Efficacy and safety of omalizumab in patients with chronic idiopathic / spontaneous urticaria who remain symptomatic on $\mathrm{H} 1$ antihistamines: a randomized, placebo-controlled study. J Invest Dermatol 2015; 135:925.

25. Gericke J, Metz M, Ohanyan T, Weller K, Altrichter S, Skov PS, Falkencrone S, Brand J, Kromminga A, Hawro T, Church MK, Maurer M. Serum autoreactivity predicts time to response to omalizumab therapy in chronic spontaneous urticaria. J Allergy Clin Immunol Pract 2016; 4:529-30.

26. Palacios T, Stillman L, Borish L, Lawrence M. Lack of basophil CD203c-upregulating activity as an immunological marker to predict response to treatment with Omalizumab in patients with symptomatic chronic urticaria. J Allergy Clin Immunol Pract 2015; Dec 24. Doi: 10.1016/j.jaip. 2015.11.025. (Epub ahead of print).

27. Raap U, Wieczorek D, Gehring M, et al. Increased levels of serum IL-31 in chronic spontaneous urticaria. Exp Dermatol 2010; 19:464-6.
28. Altrichter S, Hawro T, Hanel K, Czaja K, Luscher B, Maurer M, Church MK, Baron JM. Successful omalizumab treatment in chronic spontaneous urticaria is associated with lowering of serum IL-31 levels. J Eur Acad Dermatol Venereol 2016; 30:454-5.

29. Asero R, Marzano AV, Ferrucci S, Cugno M. D-Dimer plasma levels parallel the clinical response to omalizumab in patients with severe chronic spontaneous urticaria. Int Arch Allergy Immunol 2017; 172:40-4.

30. Grattan CE, O’Donnell BF, Francis DM, Niimi N, Barlow RJ, Seed PT, Kobza Black A, Greaves MW. Randomized double-blind study of cyclosporin in chronic 'idiopathic' urticaria. Br J Dermatol. 2000; 143:365-72.

31. Vena GA, Cassano N, Colombo D, Peruzzi E, Pigatto P; Neo-I-30 Study Group. Cyclosporine in chronic idiopathic urticaria: a double-blind, randomized, placebo-controlled trial. J Am Acad Dermatol. 2006; 55:705-9.

32. Doshi DR, Weinberger MM. Experience with cyclosporine in children with chronic idiopathic urticaria. Pediatr Dermatol 2009; 26:409-13.

33. Iqbal K, Bhargava K, Skov PS, Falkencrone S, Grattan CE. A positive serum basophil histamine release assay is a marker for cyclosporine-responsiveness in patients with chronic spontaneous urticarial. Clin Transl Allergy 2012; 2:19.

34. Hollander SM, Joo SS, Wedner HJ. Factors that predict the success of cyclosporine treatment for chronic urticaria. Ann Allergy Asthma Immunol 2011; 107:523-8.

35. Asero R. Plasma D-dimer levels and clinical response to cyclosporine in severe chronic spontaneous urticaria. J Allergy Clin Immunol 2015; 135:1401-3.

36. Baek YS, Jeon J, Kim JH, Oh CH. Severity of acute and chronic urticaria correlates with D-dimer level, but not C-reactive protein or total IgE. Clin Exp Dermatol 2014; 39: 795-800. 